\title{
CORRECTION
}

\section{Correction to: Regulation of a Class of Nonlinear Systems with Unknown Growth Rate Under Uncertain Measurement Sensitivity}

\author{
Sang-Young $\mathrm{Oh}^{1} \cdot \mathrm{Ho}^{-L_{i m} \mathrm{Choi}^{1}}{ }^{10}$
}

Published online: 21 June 2021

(c) The Korean Institute of Electrical Engineers 2021

\section{Correction to: \\ Journal of Electrical Engineering \& Technology https://doi.org/10.1007/s42835-021-00783-9}

Due to an unfortunate oversight during the correction process the acknowledgement has been omitted. It should read:

This work was supported by the National Research Foundation of Korea (NRF) Grant funded by the Korea government (MSIT) (No. NRF-2019R1F1A1040968).

The original article has been corrected.
Publisher's Note Springer Nature remains neutral with regard to jurisdictional claims in published maps and institutional affiliations.

The original article can be found online at https://doi.org/10.1007/ s42835-021-00783-9.

Ho-Lim Choi

hlchoi@dau.ac.kr

Sang-Young Oh

syoh1@donga.ac.kr

1 Department of Electrical and Electronic Engineering,

Dong-A University, 840 Hadan2-Dong, Saha-gu,

Busan 604-714, Korea 